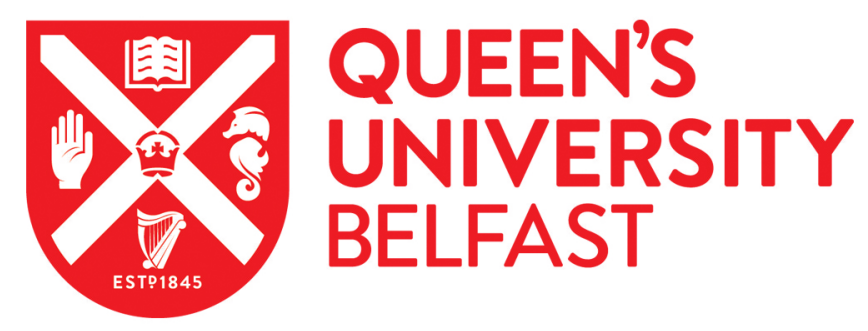

\title{
3D FEM simulation of helical milling hole process for titanium alloy Ti- $6 \mathrm{Al}-4 \mathrm{~V}$
}

Ji, C., Li, Y., Qin, X., Zhao, Q., Sun, D., \& Jin, Y. (2015). 3D FEM simulation of helical milling hole process for titanium alloy Ti-6Al-4V. International Journal of Advanced Manufacturing Technology, 81(9), $1733-1742$. https://doi.org/10.1007/s00170-015-7323-8

\section{Published in:}

International Journal of Advanced Manufacturing Technology

\section{Document Version:}

Peer reviewed version

\section{Queen's University Belfast - Research Portal:}

Link to publication record in Queen's University Belfast Research Portal

\section{Publisher rights}

(C) 2015 Springer International Publishing AG

The final publication is available at Springer via http://link.springer.com/article/10.1007\%2Fs00170-015-7323-8.

\section{General rights}

Copyright for the publications made accessible via the Queen's University Belfast Research Portal is retained by the author(s) and / or other copyright owners and it is a condition of accessing these publications that users recognise and abide by the legal requirements associated with these rights.

Take down policy

The Research Portal is Queen's institutional repository that provides access to Queen's research output. Every effort has been made to ensure that content in the Research Portal does not infringe any person's rights, or applicable UK laws. If you discover content in the Research Portal that you believe breaches copyright or violates any law, please contact openaccess@qub.ac.uk. 


\title{
3D FEM simulation of helical milling hole process for titanium alloy Ti-6Al-4V
}

\author{
Chunhui Ji $\cdot$ Yonghang Li $\cdot$ Xuda Qin $\cdot$ Qing Zhao $\cdot$ Dan Sun $\cdot$ Yan Jin
}

Abstract As an emerging hole-machining methodology, helical milling process has become increasingly popular in aeromaterials manufacturing research, especially in areas of aircraft structural parts, dies, and molds manufacturing. Helical milling process is highly demanding due to its complex tool geometry and the progressive material failure on the workpiece. This paper outlines the development of a 3D finite element model for helical milling hole of titanium alloy Ti-6Al-4V using commercial FE code ABAQUS/Explicit. The proposed model simulates the helical milling hole process by taking into account the damage initiation and evolution in the workpiece material. A contact model at the interface between end-mill bit and workpiece has been established and the process parameters specified. Furthermore, a simulation procedure is proposed to simulate different cutting processes with the same failure parameters. With this finite element model, a series of FEAs for machined titanium alloy have been carried out and results compared with laboratory experimental data. The effects of machining parameters on helical milling have been elucidated and the capability and advantage of FE simulation on helical milling process have been well presented.

Keywords: Finite element model, Helical milling hole, 3D, Titanium alloy

\section{Introduction}

Titanium alloys are used extensively in aerospace for the combined high special strength (strength-to-weight ratio), fracture-resistant characteristics, and exceptional resistance to corrosion. However, titanium alloys are usually considered as extremely difficult to cut material because of their low thermal conductivity and high chemical reactivity with cutting tool materials [1]. During an aircraft assembly process, hundreds of boreholes need to be produced through riveting or bolting. Poor quality boreholes and serious tool wear are common problems in traditional drilling processes as a result of poor heat dissipation and large thrust force experienced by the material [2-5]. Being one of the new hole-machining methodologies, helical milling (orbital drilling) can achieve smooth cutting process, small thrust force, and high accuracy simultaneously.

A number of recent research efforts have been directed towards the helical milling technique. Ni [6] presented a helical milling technique deploying special devices and tools, and the machining dynamics and cutter performance have been studied for helical milling of aerospace aluminum alloy, titanium alloy, and carbon fiber-reinforced plastic (CFRP) materials. Iyer et al. [7] carried out a comparative study of traditional drilling techniques and technologies in the helical milling cutting forces and hole quality in AISI D2 tool steel. Brinksmeier et al. [8] described the theoretical model of helical milling kinematics with consideration of the

C. H. Ji, Y. H. Li, X. D. Qin ( $₫)$,Q. Zhao

Tianjin Key Laboratory of Equipment Design and Manufacturing Technology,

Tianjin University, Tianjin City 300072, People's Republic of China

email: qxd@tju.edu.cn

D. Sun, Y. Jin

School of Mechanical and Aerospace Engineering,

Queen's University Belfast, United Kingdom 
geometrical relation between periphery cutting zone and bottom cutting zone. Denkena et al. [9] investigated the influence of the axial and tangential feed on cutting forces and borehole quality during the helical milling of stack materials consisting of CFRP and titanium alloy. Liu et al. [10] presented a 3D heat transfer model to describe the temperature distribution with the time variation in solid with conduction-convection boundary during the helical milling process, and the effects of different cutting parameters on the temperature rise were detailly investigated with this model. Sadek et al. [11] studied the effects of the helical milling process parameters on the hole quality, and the results showed significant enhancement in the hole quality compared to conventional drilling, due to the reduced axial force and cutting temperature, resulting from the redistribution of the load exerted by cutting edges.

The machining principle of helical milling is to use a special end-mill, and deploys the similar continuous process as in general end milling, but with tool center path being a spiral instead of a straight line. The process not only contains a radial feed but also an axial feed and can be used to machine bevel, groove and borehole. Helical milling is to certain extent similar to circular milling. In general, circular milling is performed in the XOY plane with a constant axial depth of cut, followed by axial plunging at a fixed increment and subsequent circular milling operations. While in the helical milling process, the milling tool gradually moves in the axial direction with a helical motion as it traverses around a circle in milled cylinder holes. The helical milling principle is shown in Fig. 1.

\section{[Insert Figure 1 here]}

Recently, high volume of research on helical milling has been published for both experimental study and cutting kinematics [12-13]. Li et al. [14] established a three-dimensions (3D) surface topography simulation model base on an improved Z-map model to simulate the surface finish profile generated after a helical milling operation. A novel dynamic cutting force model is also proposed for helical milling process on the basis of a quantitative description of cutting zones corresponding to helical milling operation, in which the cutting mechanism and the cutting force contribution on both the peripheral and the front cutting edges are taken into consideration simultaneously [15]. Liu et al. [16] proposed an cutting force model to predict the cutting force and torque in a helical milling operation as a function of spindle speed, helical feed, radial and axial cutting depth and cutter geometry. However, very few finite element analysis studies have been reported for the prediction of cutting force and torque. Jin et al. [17] predicted the micro-milling forces with an FE model of orthogonal micro-cutting of brass. Zhang et al. [18] simulated the 2D orthogonal cutting operation for Ti-6Al-4V alloy with software ABAQUS, and presented a multi-physic comprehension related to chip formation, cutting forces, temperature evolutions, and surface integrity. Calamaz et al. [19] implemented a new material constitutive law to analyze the chip formation and shear localisation when orthogonal machining titanium alloys. Chip morphology, cutting and feed forces are all well predicted by the 2D finite element model. Shams et al. [20] improved the orthogonal cutting simulation with the established nonlocal damage model, and the Johnson-Cook damage criterion is used to compare local and nonlocal model results.

Some investigators began to build a 3D FEM to investigate the cutting process. Li et al. [21] presented the finite element modeling of 3D turning of titanium with Third Wave AdvantEdge machining simulation software, and the measured cutting forces and chip thickness are compared to the finite element modeling results with 
good agreement. Wu et al. [22] proposed a simplified and idealized FE model to simulate the drilling process and predict drilling forces of titanium alloy Ti-6Al-4V. Latterly, the more real 3D finite element model (FEM) for the milling process of Ti-6Al-4V alloy was developed with the Johnson-Cook material constitutive equation, considering the effects of strain, strain rate, and temperature on material properties. The experimental results confirmed the capability and advantage of 3D FEM simulation in the complex milling process of titanium [23]. However, the helical milling hole process is more complex than the traditional drill or milling process. In this work, the helical milling hole process of Ti-6Al-4V alloy is firstly investigated using $3 \mathrm{D}$ finite element analysis. The model aims to predict induced cutting forces, chip form, stress distribution in the workpiece throughout the helical milling hole process based on real milling geometry and process parameters.

\section{Finite element model}

In this study a finite element model based on Lagrangian formulation is developed to simulate the helical milling process. A 3D model of drilling process is developed using a commercial finite element software ABAQUS/Explicit. Due to the dynamic nature of the process, dynamic explicit finite element integration has been proposed for this study. The FE analysis is time dependent due to the strain rate effect and process parameters. Details of the FE model are discussed as follows.

\subsection{Materials: workpiece and tools}

The workpiece used was a Ti-6Al-4V plate $(40 \mathrm{~mm} \times 40 \mathrm{~mm} \times 5 \mathrm{~mm})$ used in this work was supplied by BAOJI TITANIUM INDUSTRY CO., LTD in china. The main physical, mechanical and thermal properties are shown in Table 1.

[Insert Table 1 here]

Where $\rho$ is density, $v$ is Possion's ratio, $E$ is young modulus, $\sigma_{y}$ is yield strength, $\sigma_{u}$ is tensile strength, $C_{p}$ is specific heat capacity, $K$ is conductivity.

The helical milling tests have been performed using $6 \mathrm{~mm}$ diameter TiAlN coated tungsten carbide end-mills with a $35^{\circ}$ helix angle and a $5^{\circ}$ rake angle. These are specially designed for producing boreholes in helical milling processes.

\subsection{Geometry, Mesh and Elements}

Accurate tool geometry model is important for precise prediction of cutting force in helical milling. For this purpose, a complex 3D end-mill cutter is modeled using CATIA software and imported into the software ABAQUS for simulation of helical milling hole process of Ti-6Al-4V alloy. The initial mesh and assembly are shown in Fig. 1, the helical milling cutter is modeled as a rigid body because the rigidity of cutter is far larger than the rigidity of workpiece, and its mass and inertia are also considered to describe the equivalent kinematics of the process.

Optimizing the mesh used in this simulation is not trivial and has been one of the subjects in our research. Considering the very complicated geometry and the need for extremely high computing resources, a balance 
between the high accuracy results and reasonable element size needs to be achieved. The mesh presented here in Fig. 2 is the mesh optimized through a comprehensive mesh and conversion study. The detailed mesh study will not be discussed here as it is not the main objective of this study. To capture the large stress gradients accurately, the mesh in the helical milling area have been refined. The mesh in regions outside the cutting area has been set to be sparse to reduce computation time. The numerical workpiece model is made of 243,600 hex elements with element size of $0.2 \mathrm{~mm}$ in refined area, and the element type is C3D8RT. The workpiece size is $40 \mathrm{~mm} \times 40$ $\mathrm{mm} \times 5 \mathrm{~mm}$. The helical milled hole diameter is $10 \mathrm{~mm}$ and the milled hole depth is $5 \mathrm{~mm}$. The cutter model has 105,798 elements and the element type is R3D4T. The helical milling cutter has four teeth, the helical angle is $35^{\circ}$ and the rake angle is $5^{\circ}$. The whole simulation time is about $320 \mathrm{~h}$ when use Dell workstation with $32 \mathrm{G}$ of memory.

[Insert Figure 2 here]

\subsection{Constitutive model}

Johnson-Cook constitutive model [24] has been adopted for the milling process. Johnson-Cook constitutive model is one of the widely used models in high strain rate applications. The flow stress of materials is calculated according to Eq. (1).

$$
\sigma=\left(A+B \varepsilon^{n}\right)\left(1+C \ln \frac{\dot{\varepsilon}}{\dot{\varepsilon}_{0}}\right)\left[1-\left(\frac{T-T_{0}}{T_{m}-T_{0}}\right)^{m}\right]
$$

Where $\varepsilon$ is the equivalent plastic strain, $\dot{\varepsilon}$ and $\dot{\varepsilon}_{0}$ are the equivalent and reference plastic strain rates, $T, T_{m}$ and $T_{0}$ are the material's cutting zone, melting and room temperature, respectively. $n$ is the strain hardening index and $m$ is the thermal softening index. And $A, B$, and $C$ represent the yield strength, strain, and strain rate sensitivities of the material, respectively. The detail constitutive material model parameters are shown in Table 2.

[Insert Table 2 here]

Progressive damage behaviour of the workpiece materials is captured for each element, and the failure criterion developed by Johnson-Cook [25] has been used for the damage initiation. The damage initiation is derived from Eq. (2). When the damage parameter, $\omega_{D}$, reaches 1.0, the damage initiates.

$$
\omega_{D}=\int \frac{d \bar{\varepsilon}^{p l}}{\bar{\varepsilon}_{D}^{p l}}
$$

In the equation above, the equivalent plastic strain at the onset of damage, $\bar{\varepsilon}_{D}^{p l}$, is calculated from Eq. (3), and values of corresponding parameters are listed in Table 3.

$$
\bar{\varepsilon}_{D}^{p l}=\left[d_{1}+d_{2} \exp \left(d \frac{p}{3_{q}}\right)\right]\left[1+d \ln \left(\frac{\dot{\bar{\varepsilon}}^{p l}}{\dot{\varepsilon}_{0}}\right)\right]\left(1+d \frac{T-T_{0}}{T_{m}^{5}-T_{0}}\right)
$$

Where $d_{l} \sim d_{5}$ are the failure parameters of Johnson-Cook damage model, $p$ is the hydrostatic pressure, $q$ is the Mises stress, $\dot{\varepsilon}_{0}$ is the reference strain rate, and $\dot{\bar{\varepsilon}}^{p l}$ is the strain at the time of failure. 
[Insert Table 3 here]

In this study, parts of these constitutive material model parameters of Ti-6Al-4V (Tables 2 and 3) have been derived from the related equations provided, as well as from literature [26].

The progressive damage evolution is assumed linear with the plastic displacement. The evolution of the damage is specified with the displacement criteria and the damage evolution operator, $D$, can be computed from equation (4).

$$
D=\frac{L_{C} \bar{\varepsilon}_{0}^{p l}}{\bar{u}_{f}^{p l}}=\frac{\bar{u}^{p l}}{\bar{u}_{f}^{p l}}
$$

The effective stress of an element after damage initiation can be computed from equation (5). As the damage evolution operator reaches 1.0 , it is assumed that the element is completely failed.

$$
\bar{\sigma}=(1-D) \sigma
$$

In the Eqs. (4) and (5), D is damage evolution criterion, $L_{c}$ is the characteristic length of an element, $\bar{\varepsilon}_{0}^{p l}$ is the equivalent plastic strain at the onset of damage, $\bar{u}^{p l}$ is the plastic displacement, $\bar{u}_{f}^{p l}$ is the plastic displacement at failure.

The cutting tool was modeled as a rigid body. Mass and inertia of the 3D complex end-mill geometry have been considered in the analysis to model the equivalent kinematics of the process.

\subsubsection{Contact model}

Estimation of friction in a machining process is very complicated and has remained a challenge in research. It is widely accepted that the friction at the tool-workpiece interface can be represented by a relationship between the normal and frictional stress over the cutting edges of the tool. Helical milling not only involves end cutting, but also periphery cutting, hence the friction can occur at four interfaces: (a) the end cutting flank face edge-workpiece interface, (b) the end cutting rake face edge-chip interface, (c) the periphery cutting flank face edge-workpiece interface, and (d) the periphery cutting rake face edge-chip interface. In this study, because of the high cutting speed and larger size of element in cutting area, the continuous chip generated cannot be observed during the cutting process, but can be modeled instead. Therefore the friction between the chip and end-mill has been taken into account. Based on the Coulomb friction model in equation (6), it is assumed that the frictional stress on the cutter is proportional to the normal stress with a constant friction coefficient.

$$
\tau_{n}=\mu \sigma_{n}
$$

Where $\tau_{n}$ is the frictional stress; $\sigma_{n}$ is the normal stress; $\mu$ is friction coefficient. In the present study, the interaction between the workpiece and the tool is modeled based on Lagrangian mechanics, using pressure-overclosure algorithm and surface-surface contact model which has been built in ABAQUS/Explicit. Isbilir and Ghassemieh [26] have recommended a friction coefficient between $0.5 \sim 0.6$ for drilling process of Ti-6Al-4V. Since the coolant is used in our process, a value of 0.5 is considered.

\subsubsection{Boundary conditions and Loading}


The bottom and two vertex surfaces of the workpiece are fixed in $\mathrm{X}, \mathrm{Y}$ and $\mathrm{Z}$ directions $\left(u_{x}=u_{y}=u_{z}=0\right)$. The freedom of rotation in $\mathrm{X}$ and $\mathrm{Y}$ has been constrained for the end mill $\left(R_{x}=R_{y}=0\right)$, so that the tool is only able to move and rotate along Z-axis and move across the X-Y plane. The movement of the end mill in the X-Y plane (X and Y directions), has been defined by Eq. (7).

$$
x=A_{1}+A_{2} \cos (\omega \cdot t) \quad y=B_{2} \sin \omega .
$$

Because of the vertical configuration of the machining system, coolant can be rarely used. All tests in this study were carried out with air-cooling. The temperature of helical mill head measured immediately after the cutting process stabilized in the range $160 \sim 200^{\circ} \mathrm{C}$. Therefore we estimate that the reference test temperature $\left(T_{0}\right)$ is approximately $180^{\circ} \mathrm{C}$. Considering under such temperature no crystalline phase transformation would take place, a pure mechanical simulation was therefore considered with no inclusion of the heat transfer or thermal effect. We assumed temperature change has minimum impact with air coolant being used, hence the heat generation has not been considered in this study to minimize computational time.

\section{Experimental set up}

To verify the finite element model, helical milling trials were conducted using DMC-75V linear five-axis machine center with maximum spindle speed of 28,000 rpm and maximum feed rate of 9,000 mm/min. A Kistler three-direction stationary dynamometer (model 9225B) and a supporting Kistler charge amplifier (model 5070) were used to collect the data of cutting force, and Matlab software was utilized for data analysis. The detailed helical milling experimental setup for Ti-6Al-4V is given in Fig. 3. The target hole diameter was chosen to be 10 $\mathrm{mm}$, which is commonly used in the aircraft industry.

[Insert Figure 3 here]

In order to control the tool wear and reduce computation time, relatively low values of cutting parameters have been deployed, as shown in Table 4. To investigate the effects of cutting parameters on helical milling, finite element analyses have been performed with ten varying combinations of cutting speeds, orbital speeds and axial feeds. Each of the conditions was tested three times and mean values of the results are reported. For each test, new tool has been used and the effect of gradual tool wear has been neglected.

[Insert Table 4 here]

During milling, the dynamometer was charged and signals were collected by the amplifier and transferred to the Kistler Dynoware software. Measurements were done at a frequency of 1,000 $\mathrm{Hz}$ throughout the helical milling process. The data of cutting force was analyzed using the Matlab software.

\section{Results and Discussion}

Thermal conditions are not considered in the model due to the effective cooling (by cold compressive air) used 
during the helical milling hole process. Also Liu et al. [10] found that the cutting temperature in helical milling of Ti-6Al-4V alloy is always below $200^{\circ} \mathrm{C}$ when the spindle speed in the range of 3,300 3,900 rpm and axial feed in the range of $0.1 \sim 0.2 \mathrm{~mm} / \mathrm{rev}$. In the helical milling process, three components of the resultant forces will be produced, as the cutting force in Y-axis is completely symmetrical to that of $\mathrm{X}$-axis and has not been presented here, hence only the cutting force of X-axis (feed force) and cutting force of Z-axis (thrust force) are investigated in this work.

In order to validate the FE model, it is necessary to compare the simulation results against the experimental data. Fig. 4 shows the comparison of experimental and simulated results for (a) thrust force and (b) feed force under a typical test condition parameters $(2,000 \mathrm{rpm}$ spindle speed, $320 \mathrm{~mm} / \mathrm{min}$ orbital speed and $0.15 \mathrm{~mm} / \mathrm{rev}$ axial feed).

\section{[Insert Figure 4 here]}

It was found from Fig. 4a that the average thrust force and feed force in the experimental trial was $179 \mathrm{~N}$ and $127 \mathrm{~N}$ respectively. Whereas those suggested by the FE modeling were $164 \mathrm{~N}$ and $109 \mathrm{~N}$, respectively. Note the value of the feed force reported was the mean value of the maximum.

Greater deviation has been seen between experimental and simulation data during the initial and ending stage, therefore data analysis has been mainly focused on the intermediate (stabilized) cutting stage. Also, small deviation $(<10 \%)$ has been found between average experimental and simulation results under the test conditions, which suggested that the developed model is able to predict the thrust force and feed force with a reasonable level of accuracy. Comparison between experimental and simulation results have also been performed for other process parameters and similar level of agreement have been observed, the details of which has been discussed in the following section.

\subsection{The cutting force}

The thrust force during helical milling of Ti-6Al-4V under different cutting conditions has been estimated by FE model and also was measured by helical milling experiments. The experimental and modeling data are shown in Tables 5 and 6, respectively. The FE model estimated the thrust force with errors between 3 25\% depending on the machining parameters. Seen from Tables 5 and 6, it should be noted that not all the machining processes can be predicted accurately when only considering the components mechanical properties. The FE model generally underestimated the thrust forces, this is possibly caused by the assumption of constant reference test temperature $\left(\mathrm{T}_{0}=180^{\circ} \mathrm{C}\right)$ which was reported in [10]. However the actual tool temperature cannot be a constant throughout the milling process. In addition, the dynamometers itself comes with a measurement error of about 5\%. A more realistic friction model, tool wear and the rigid tool are all important factors which could contribute to the results of simulation.

[Insert Table 5 here]

[Insert Table 6 here] 
From Tables 5 and 6, it is also found that the thrust force is increased with the increasing orbital speed and axial feed, but decreased with increasing spindle speed. The thrust force measured is between $179 \mathrm{~N}$ and $285 \mathrm{~N}$ and ranged from $154 \mathrm{~N}$ to $257 \mathrm{~N}$ predicted by the FE model depending on the cutting parameters. And the maximum thrust force has also been produced under condition C3-4.

\subsection{Effect of spindle speed}

In helical milling, the variation of the spindle speed has significant effects on the cutting force in the cutting region. A drop in thrust force and feed force has been observed with the increase of spindle speed as shown in Fig. 5, where the simulation and experimental results are in good agreement. The experiments followed the condition: orbital speed $320 \mathrm{~mm} / \mathrm{min}$, axial feed $0.2 \mathrm{~mm} / \mathrm{rev}$ and a series of different spindle speeds (C1-1 C1-4).The increase in spindle speed from 1500 to $3000 \mathrm{rpm}$ has caused a significant decrease of 55\% (experimental) and 63\% (simulation) in thrust force and a 16\% (experimental) and 24\% (simulation) decrease in feed force.

[Insert Figure 5 here]

\subsection{Effect of orbital speed}

The thrust force and the feed force are also greatly affected by the orbital speed in helical milling of Ti-6Al-4V. Fig. 6 shows that for both simulation and experimental data, both the thrust and feed forces are increased with increasing orbital speed under the typical test condition of spindle speed $2000 \mathrm{rpm}$, axial feed $0.2 \mathrm{~mm} / \mathrm{rev}$ and a series of different orbital speeds (C2-1 C2-4). Seen from Fig. 6, as the orbital speed increases from 200 to 320 $\mathrm{mm} / \mathrm{min}$, an increase of $18 \%$ (experimental) and $13 \%$ (simulation) has been found for the thrust force, and an increase of $23 \%$ (experimental) and $16 \%$ (simulation) for the feed force.

[Insert Figure 6 here]

\subsection{Effect of axial feed}

Fig. 7 illustrates the trend under conditions of spindle speed $2000 \mathrm{rpm}$, orbital speed $320 \mathrm{~mm} / \mathrm{min}$ and a series of different axial feeds (C3-1 C3-4). When the axial feed increases from 0.15 to $0.3 \mathrm{~mm} / \mathrm{rev}$, an increase of $63 \%$ (measured value) and 56\% (predicted value) have been found in thrust force, and 18\% (measured value) and $48 \%$ (predicted value) increase for the feed force. See from Figs. 5-7, we can conclude that the main factors affecting the thrust force are the spindle speed and axial feed, and the main factor affecting feed force is the axial feed. Effect of orbital speed is less significant than the spindle speed or the axial feed. Similar trends of process parameters and thrust force have been reported for titanium alloys elsewhere [13]. 


\subsection{Workpiece stress distribution}

The progressive damage and the stress distributions in helical milling hole process of Ti-6Al-4V under condition of spindle speed $2000 \mathrm{rpm}$, orbital speed $320 \mathrm{rpm}$, and axial feed $0.15 \mathrm{~mm} / \mathrm{rev}$ (Case: C3-1) are shown in Fig. 8. As can be seen from the Fig. 8, the stress is induced as the end-mill touches the workpiece material and damage develops gradually as the helical milling process progresses. When the damage variables reach their limit, elements are failed and removed from the model. The induced Mises stress in the drilling area of the titanium alloy workpiece was approximately $1 \mathrm{GPa}$. The stress in the workpiece gradually decreased as moving away from the helical milling zone and the stress around the borehole was approximately $300 \mathrm{MPa}$. This is in good agreement with the actual experimental value of $320 \mathrm{MPa}$ (the experiments on the surface of the borehole machining residual stress is not the focus of this the paper, hence details will not be presented here). It was found from the experiment and simulation that the cutting force of the helical milling was smaller than that of other traditional drilling processes. This also infers a smaller stress for the helical cutting process, so the end-mill may experience less serious wear. This may also indicate a better surface quality of the borehole and smaller deformation around the borehole.

\section{[Insert Figure 8 here]}

\subsection{Chip formation}

No continuous chip formation has been observed in Fig. 8. The fact that the process of helical milling process is intermittent is one of the main reasons why the thrust force of helical milling is smaller than that of drilling. So it is reasonable not to see continuous chip forming during the helical milling process. The intermittent chip has been observed in the Fig. 9a from the result of FE simulation (Test conditions: spindle speed 2000 rpm, orbital speed $320 \mathrm{rpm}$, axial feed $0.15 \mathrm{~mm} / \mathrm{rev}$ ). This is true as no continuous chip can be generated when the cutting speed is equal or greater than $60 \mathrm{~m} / \mathrm{min}$ (equivalent to $3300 \mathrm{rpm}$ ) [19, 27]. When the spindle speed and orbital speed were reduced deliberately (Test conditions: spindle speed $20 \mathrm{rpm}$, orbital speed $10 \mathrm{rpm}$, axial feed 0.2 $\mathrm{mm} / \mathrm{rev}$ ), continuous chip formation can be observed, as is shown in Fig. 9b. The modeling result has confirmed that the Johnson-Cook model can be applied to the helical milling process.

[Insert Figure 9 here]

\section{Conclusions}

In this paper, helical milling of titanium alloy is studied. A 3D finite element model based on a mechanical Lagrangian formulation is used to simulate the helical milling process of Ti-6Al-4V.

Johnson-Cook constitutive material model is implemented and the study showed that this model may be applied for helical milling simulation under conditions where intermittent chip is generated.

The effects of cutting parameters, such as spindle speed, orbital speed and axial feed, on forces are investigated by the proposed FE model. Results show that cutting parameters have significant influence on the 
thrust force. The predictions of thrust force using the FE model closely match the experimentally measured values, confirming the accuracy of the developed model. Results clearly show that the induced thrust force increases with increasing axial feed and decreases with the spindle speed. The spindle speed and axial feed have greater influence on the thrust force and the feed force than the orbital speed. The model has also shown that incorporation of a mechanical model is feasible to predict the helical milling process.

\section{Acknowledgments}

The authors are grateful for funding supports by National High-tech R\&D Program of China (863 Program) (2013AA040100). National Natural Science Foundation of China (51275345, 51405336), and National Engineering and Research Center for Commercial Aircraft Manufacturing (SAMC13-JS-15-030).

\section{References}

1. Machado AR, Wallbank J (1990) Machining of titanium and its alloys-a review. Proc Inst Mech Eng 204:53-60

2. Sharif S, Rahim EA (2007) Performance of coated-and uncoated-carbide tools when drilling titanium alloy-Ti6Al4V. J Mater Process Technol 185:72-76

3. Canteroa JL, Tardío MM, Canteli JA, Marcos M, Miguéle MH (2005) Dry drilling of alloy Ti-6Al-4V. Int J Mach Tools Manuf 45:1246-1255.

4. Erween AR, Safian S (2006) Investigation on tool life and surface integrity when drilling Ti-6Al-4V and Ti -5Al-4V- Mo/Fe. JapanSoc Mech Engrs 49:340-345

5. Zeilmann RP, Weingaertner WL (2006) Analysis of temperature during drilling of Ti6Al4V with minimal quantity of lubricant. J Mater Process Technol 179:124-127

6. Ni WY (2007) Orbital drilling of aerospace materials. SAE Technical Paper 01:3814-3822

7. Iyer R, Koshy P, Ng E (2007) Helical milling: an enabling technology for hard machining precision holes in AISI D2 tool steel. Int J Mach Tools Manuf 47:205-210

8. Brinksmeier E, Fangmann S, Meyer I (2008) Orbital drilling kinematics. Prod Eng Res Devel 2:277-283

9. Denkena B, Boehnke D, Dege JH (2008) Helical milling of CFRP-titanium layer compounds. CIRP J Manuf Sci Technol 1:64-69

10. Liu J, Ren CZ, Qin XD, Li H (2014) Prediction of heat transfer process in helical milling. Int J Adv Manuf Technol 72:693-705

11. Sadek A, Meshreki M, Attia MH (2012) Characterization and optimization of orbital drilling of woven carbon fiber reinforced epoxy laminates. CIRP Ann-Manuf Techn 61:123-126

12. Qin XD, Wang Q, Wang HY (2011) Dynamic analysis of helical milling unit based on virtual machine tool. Adv Mater Res 188:463-468

13. Wang HY, Qin XD, Ren CZ, Wang Q (2012) Prediction of cutting forces in helical milling process. Int J Adv Manuf Technol 58:849-859

14. Li ZQ, Liu Q (2013) Surface topography and roughness in hole-making by helical milling. Int J Adv Manuf Technol 66:1415-1425 
15. Li ZQ, Liu Q, Ming XZ, Wang X, Dong YF (2014). Cutting force prediction and analytical solution of regenerative chatter stability for helical milling operation. Int J Adv Manuf Technol 73(1-4): 433-442.

16. Liu CY, Wang G, Dargusch MS (2012) Modeling, simulation and experimental investigation of cutting forces during helical milling operations. Int J Adv Manuf Technol 63(9-12):839-850

17. Jin X, Altintas Y (2012) Prediction of micro-milling forces with finite element method. J Mater Process Technol 212:542-552

18. Zhang Y, Umbrello D, Mabrouki T, Rizzuti S, Nelias D. Gong Y (2013) On different FE-based models to simulate cutting operation of Titanium alloy (Ti-6Al-4V). Mechanics 19(3): 349-357

19. Calamaz M, Coupard D, Girot F (2008) A new material model for 2D numerical simulation of serrated chip formation when machining titanium alloy Ti-6Al-4V. Int J Mach Tools Manuf 48: 275-288

20. Shams A, Mashayekhi M (2012) Improvement of orthogonal cutting simulation with a nonlocal damage model. Int J Mech Sci 61:88-96

21. Li R, Shih A J (2006) Finite element modeling of 3D turning of titanium. Int J Adv Manuf Technol (2006) 29: 253-261

22. Wu H, Jia Z, Zhang X, Liu G (2012) Study on simulation and experiment of drilling for titanium alloys. Mater Sci Forum 704:657-663

23. Wu HB, Zhang SJ (2014) 3D FEM simulation of milling process for titanium alloy Ti6Al4V. Int J Adv Manuf Technol 71:1319-1326

24. Johnson R, Cook WK (1983) A constitutive model and data for metals subjected to large strains high strain rates and high temperatures. The 7th International Symposium on Balistics 21:541-547

25. Johnson GR, Cook WH (1985) Fracture characteristics of three metals subjected to various strains, strain rates, temperatures and pressures. Eng Fract Mech 21:31-48

26. Isbilir O, Ghassemieh E (2013) Evaluation of drilling process in Ti6Al4V using 3D FE simulation. Int J of Machining and Machinability of Materials 13:174-190

27. Sima M, Ozel T (2010) Modified material constitutive models for serrated chip formation simulations and experimental validation in machining of titanium alloy Ti-6Al-4V. Int J Mach Tools Manuf 50:943-960 
(a)

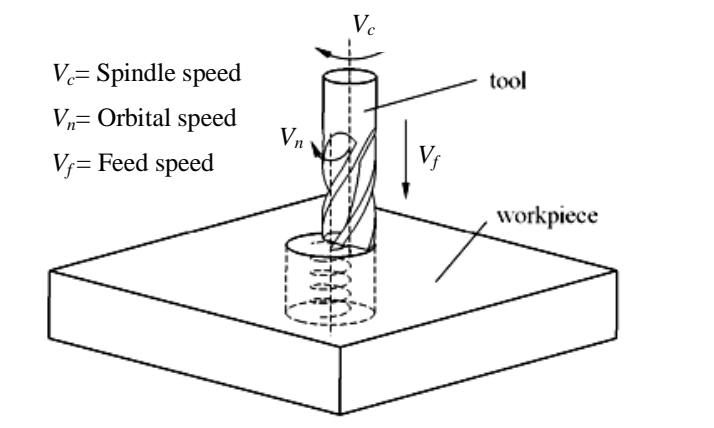

(b)

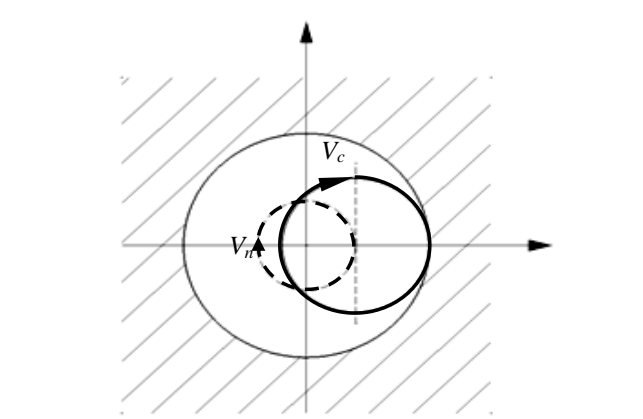

Figure 1. Schematic drawing of helical milling processes; (a) isotropic view and (b) top view the tool path

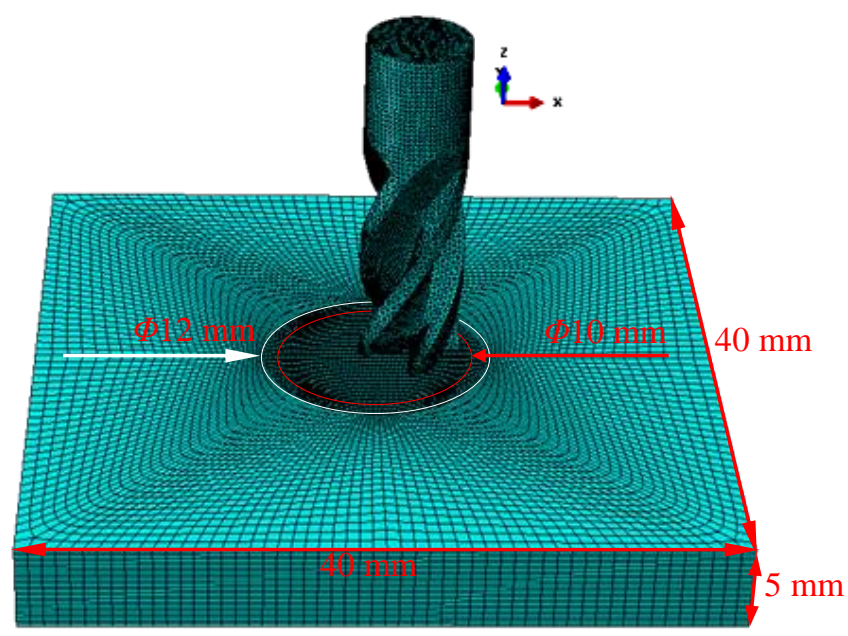

Figure 2. The geometry of the 3D finite element model

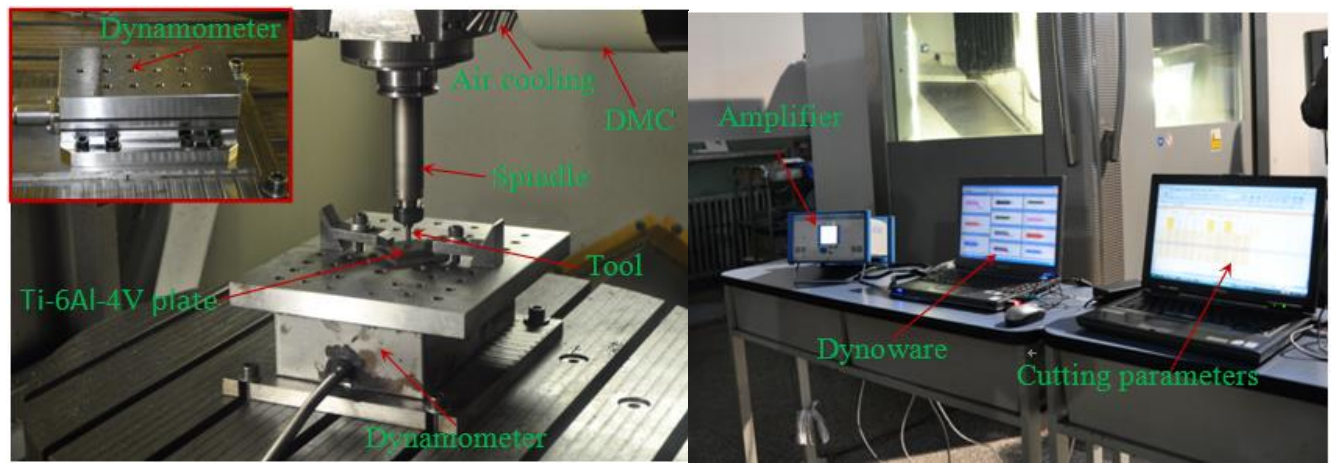

Figure 3. The helical milling experimental setup for Ti-6Al-4V alloy 
(a)

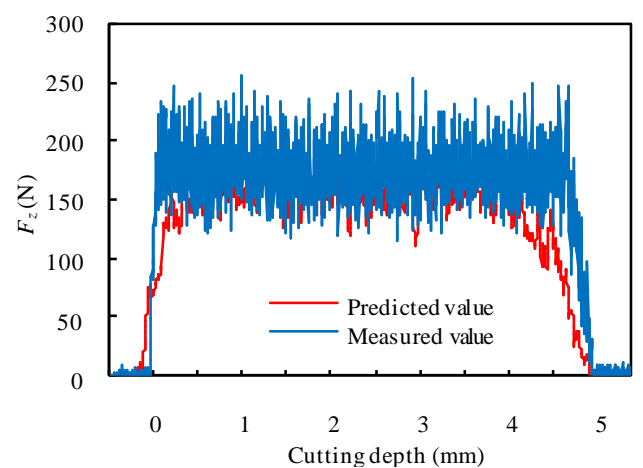

(b)

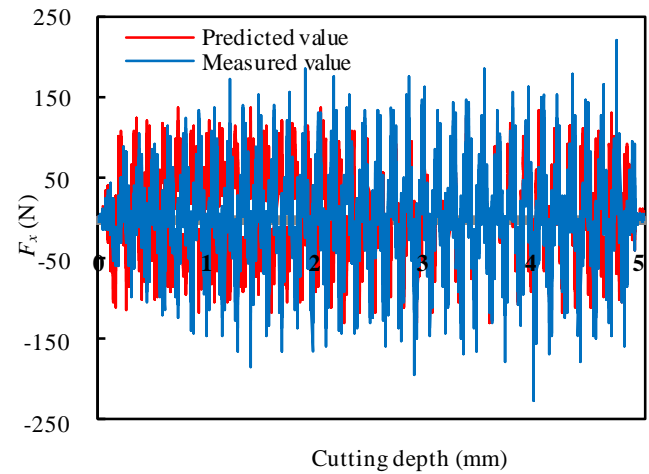

Figure 4. The comparison of experiment and simulation results: (a) thrust force and (b) feed force

(a)

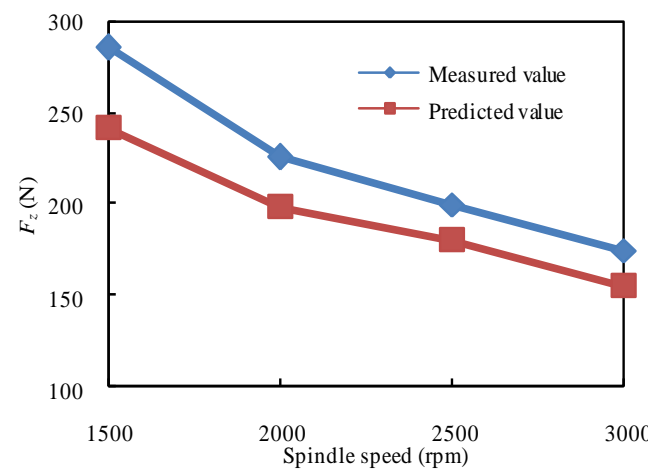

(b)

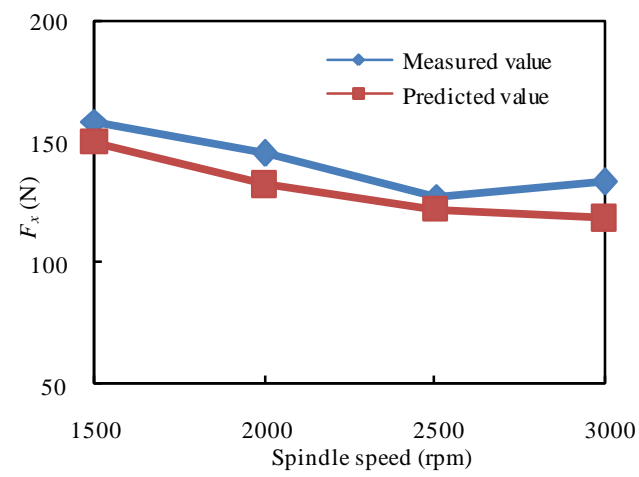

Figure 5. The effect of spindle speed on cutting force in helical milling: (a) thrust force and (b) feed force

(a)

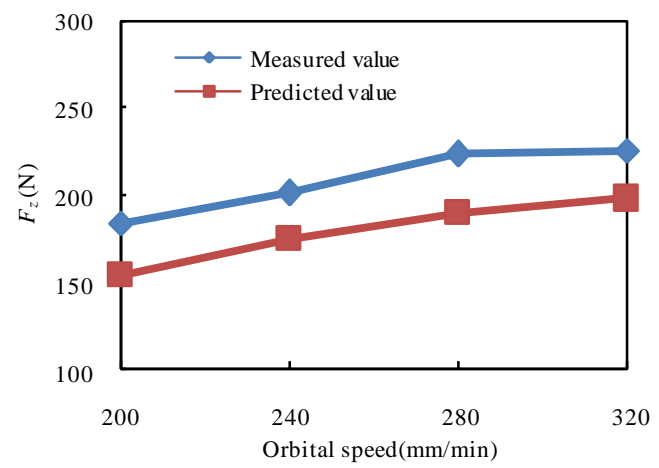

(b)

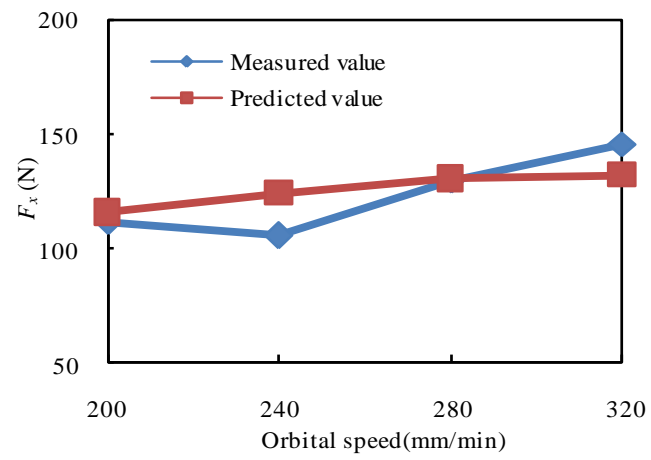

Figure 6. The effect of orbital speed on cutting force in helical milling: (a) thrust force and (b) feed force 
(a)

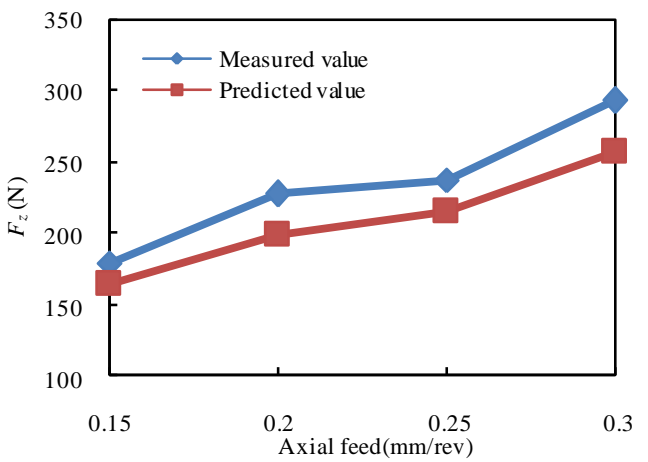

(b)

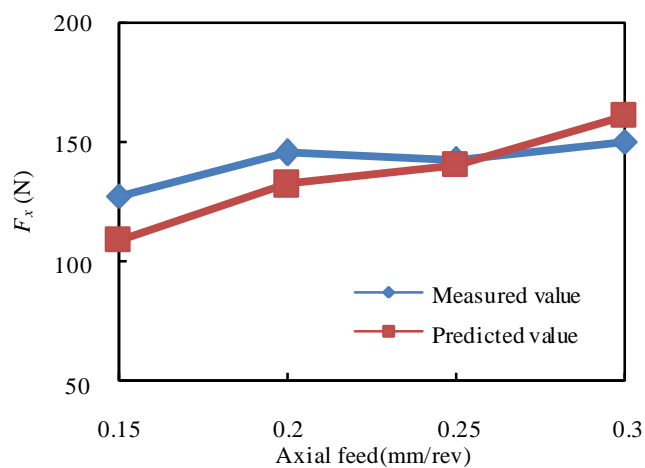

Figure 7. The effect of axial feed on cutting force in helical milling: (a) thrust force and (b) feed force

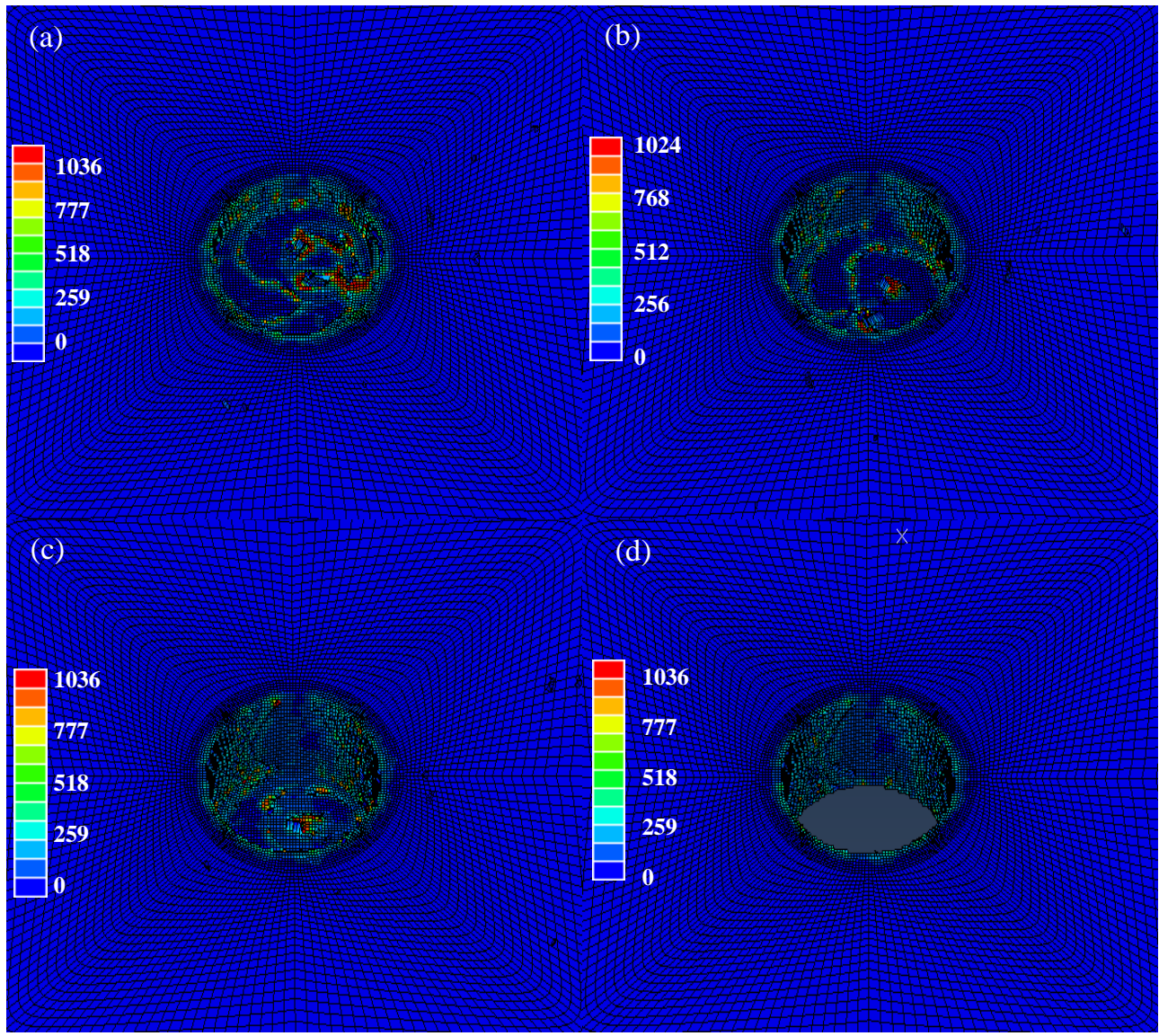

Figure 8. Stress distributions in helical milling process of Ti-6Al-4V at condition C3-1: (a) cutting depth $1 \mathrm{~mm}$, (b) cutting depth $2 \mathrm{~mm}$, (c) cutting depth $4 \mathrm{~mm}$ and (d) cutting depth $5 \mathrm{~mm}$ (Units: MPa)
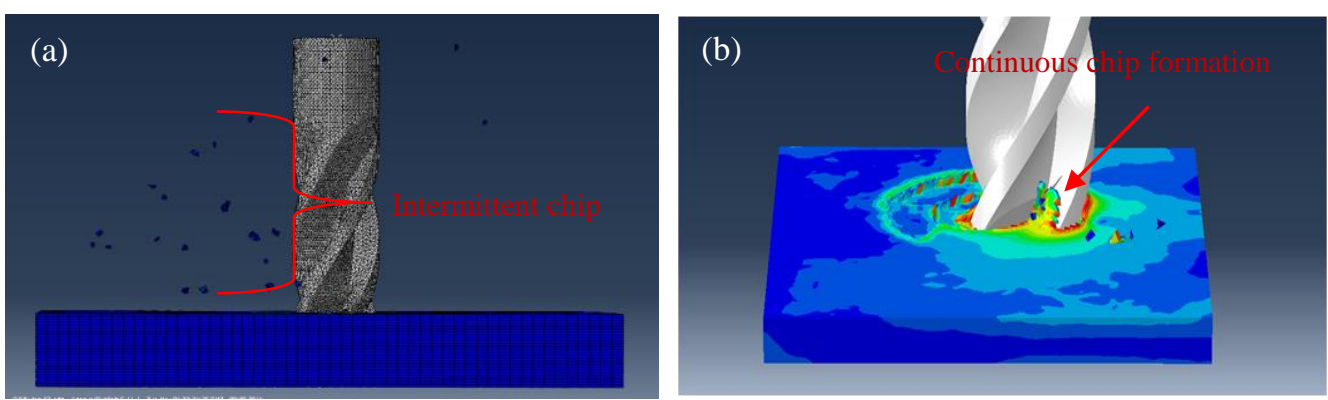

Figure 9. Chip evolution in helical milling process: (a) intermittent chip in normal cutting conditions, and (b) continuous chip formation at low spindle speed and low orbital speed 
Table 1. Material properties of Ti-6Al-4V alloy

\begin{tabular}{ll}
\hline Material properties parameters & Value \\
\hline$\rho\left(\mathrm{kg} / \mathrm{m}^{3}\right)$ & 4430 \\
$E(\mathrm{GPa})$ & 113.8 \\
$v$ & 0.342 \\
$G(\mathrm{GPa})$ & 42.1 \\
$\sigma_{y}(\mathrm{Mpa})$ & 880 \\
$\sigma_{u}(\mathrm{Mpa})$ & 950 \\
$C_{p}\left(\mathrm{~J} / \mathrm{kg} .{ }^{\circ} \mathrm{K}\right)$ & 526.3 \\
$K\left(\mathrm{~W} / \mathrm{m} .{ }^{\circ} \mathrm{K}\right)$ & 6.70 \\
\hline
\end{tabular}

Table 2. Constitutive material model parameters of Ti-6Al-4V

\begin{tabular}{ll}
\hline Constitutive material model parameters & Value \\
\hline$A$ (Mpa) & 880 \\
$B(\mathrm{Mpa})$ & 331 \\
$n$ & 0.8 \\
$C$ & 0.012 \\
$m$ & 0.34 \\
$\dot{\varepsilon}_{0}\left(\mathrm{~s}^{-1}\right)$ & 1 \\
$T_{0}\left({ }^{\circ}\right)$ & 180 \\
$T_{m}\left({ }^{\circ}\right)$ & 1605 \\
\hline
\end{tabular}

Table 3. The Johnson-Cook damage model parameters of Ti-6Al-4V

\begin{tabular}{ll}
\hline The J-C damage model parameters & Value \\
\hline$d_{1}$ & -0.09 \\
$d_{2}$ & 0.25 \\
$d_{3}$ & -0.5 \\
$d_{4}$ & 0.014 \\
$d_{5}$ & 3.87 \\
\hline
\end{tabular}

Table 4. Cutting parameters used in experiments

\begin{tabular}{lll}
\hline Spindle speed $(\mathrm{rpm})$ & Orbital speed $(\mathrm{mm} / \mathrm{min})$ & Axial feed $(\mathrm{mm} / \mathrm{rev})$ \\
\hline $1500,2000,2500,3000$ & $200,240,280,320$ & $0.15,0.2,0.25,0.3$ \\
\hline
\end{tabular}


Table 5. The cutting force of experiment

\begin{tabular}{llllll}
\hline NO. & $\begin{array}{l}\text { Spindle speed } \\
(\mathrm{rpm})\end{array}$ & $\begin{array}{l}\text { Orbital speed } \\
(\mathrm{mm} / \mathrm{min})\end{array}$ & $\begin{array}{l}\text { Axial feed } \\
(\mathrm{mm} / \mathrm{rev})\end{array}$ & \multicolumn{2}{c}{ Experimental } \\
\hline $\mathrm{C} 1-1$ & 1500 & 320 & 0.2 & 285 & 158 \\
$\mathrm{C} 1-2$ & 2000 & 320 & 0.2 & 225 & 145 \\
$\mathrm{C} 1-3$ & 2500 & 320 & 0.2 & 199 & 127 \\
$\mathrm{C} 1-4$ & 3000 & 320 & 0.2 & 174 & 133 \\
\hline $\mathrm{C} 2-1$ & 2000 & 200 & 0.2 & 184 & 111 \\
$\mathrm{C} 2-2$ & 2000 & 240 & 0.2 & 201 & 105 \\
$\mathrm{C} 2-3$ & 2000 & 280 & 0.2 & 223 & 129 \\
$\mathrm{C} 2-4$ & 2000 & 320 & 0.2 & 225 & 145 \\
\hline $\mathrm{C} 3-1$ & 2000 & 320 & 0.15 & 179 & 127 \\
$\mathrm{C} 3-2$ & 2000 & 320 & 0.2 & 227 & 145 \\
$\mathrm{C} 3-3$ & 2000 & 320 & 0.25 & 237 & 142 \\
$\mathrm{C} 3-4$ & 2000 & 320 & 0.3 & 292 & 150 \\
\hline
\end{tabular}

Table 6. The cutting force of finite element simulation

\begin{tabular}{llllll}
\hline NO. & $\begin{array}{l}\text { Spindle speed } \\
(\mathrm{rpm})\end{array}$ & $\begin{array}{l}\text { Orbital speed } \\
(\mathrm{mm} / \mathrm{min})\end{array}$ & $\begin{array}{l}\text { Axial feed } \\
(\mathrm{mm} / \mathrm{rev})\end{array}$ & $\begin{array}{l}\text { FEA } \\
F_{z}(\mathrm{~N})\end{array}$ & $F_{x}(\mathrm{~N})$ \\
\hline $\mathrm{C} 1-1$ & 1500 & 320 & 0.2 & 241 & 155 \\
$\mathrm{C} 1-2$ & 2000 & 320 & 0.2 & 198 & 132 \\
$\mathrm{C} 1-3$ & 2500 & 320 & 0.2 & 180 & 122 \\
$\mathrm{C} 1-4$ & 3000 & 320 & 0.2 & 155 & 118 \\
\hline $\mathrm{C} 2-1$ & 2000 & 200 & 0.2 & 154 & 115 \\
$\mathrm{C} 2-2$ & 2000 & 240 & 0.2 & 175 & 124 \\
$\mathrm{C} 2-3$ & 2000 & 280 & 0.2 & 190 & 130 \\
$\mathrm{C} 2-4$ & 2000 & 320 & 0.2 & 198 & 132 \\
\hline $\mathrm{C} 3-1$ & 2000 & 320 & 0.15 & 164 & 109 \\
$\mathrm{C} 3-2$ & 2000 & 320 & 0.2 & 198 & 132 \\
$\mathrm{C} 3-3$ & 2000 & 320 & 0.25 & 215 & 140 \\
$\mathrm{C} 3-4$ & 2000 & 320 & 0.3 & 257 & 161 \\
\hline
\end{tabular}

